\title{
Surfactant Apoprotein A Modifies the Inhibitory Effect of Plasma Proteins on Surfactant Activity In Vivo
}

\author{
KO YUKITAKE, CINDY L. BROWN, MUREEN A. SCHLUETER, JOHN A. CLEMENTS, \\ AND SAMUEL HAWGOOD \\ Cardiovascular Research Institute and Department of Pediatrics, University of California, \\ San Francisco, California 94143
}

\begin{abstract}
Surfactant apoprotein A (SP-A) reduces the inhibitory effects of plasma proteins on the surface tension lowering properties of pulmonary surfactant in vitro. To test the effects of SP-A in vivo we administered a complete natural dog lung surfactant (DLS) containing apoproteins SP-A, SP-B, and SP-C, a butanol extract of DLS (DLSE) containing only apoproteins SP-B and SP-C, and DLSE supplemented with SP-A intratracheally to prematurely delivered rabbit pups in the presence of increasing amounts of human plasma. In the absence of plasma DLS and DLSE (100 $\mathrm{mg} / \mathrm{kg}$ phospholipid) had comparable effects on lung mechanics (compliance during ventilation with a tidal volume of $6-7 \mathrm{~mL} / \mathrm{kg}$ and quasi-static pressure-volume behavior) in this surfactant deficiency model. Plasma proteins in increasing amounts to a maximum protein concentration of $62.5 \mathrm{mg} / \mathrm{mL}$ had no effect on the response of the pups to DLS. In contrast, plasma added to DLSE in concentrations above $20 \mathrm{mg} / \mathrm{mL}$ significantly increased the peak inspiratory pressure (PIP) required to ventilate the pups

with a tidal volume of $6-7 \mathrm{~mL} / \mathrm{kg}$, reduced the calculated total
\end{abstract}

lung compliance, and decreased the deflation lung volumes. The inhibitory effects of plasma on DLSE were significantly less when SP-A was added to DLSE (5:1, phospholipid:SP-A, wt:wt). The addition of SP-A to DLSE in plasma restored the activity of the extract to levels comparable to complete DLS. These results suggest that plasma can interfere with surfactant function and that SP-A has a significant protective effect for surfactant against the inhibitory effects of plasma in vivo. (Pediatr Res 37: 21-25, 1995)

$\quad$ Abbreviations
RDS, respiratory distress syndrome
SP, surfactant apoprotein
DLS, dog lung surfactant
DLSE, surfactant extract
PEEP, end-expiratory pressure
PIP, peak inspiratory pressure
Ctot, total dynamic compliance of the lung and chest wall

RDS of premature newborn infants is caused by a deficiency of pulmonary surfactant (1). Surfactant is a complex mixture of lipids and at least three specific proteins called SP-A, SP-B, and SP-C (reviewed in Ref. 2). SP-B and SP-C are small hydrophobic proteins that remain associated with surfactant lipids during organic solvent extraction (3). SP-A is a large oligomeric glycoprotein containing distinct collagen-like and lectin domains (4). SP-A is removed from surfactant by organic solvent extraction (3). Reconstitution studies have shown that SP-B and SP-C contribute to surfactant activity in vitro and in vivo $(5,6)$. SP-A further improves the surface activity of preparations that contain SP-B and SP-C (3) and is also required to form tubular myelin (7). Tubular myelin is the structural form of secreted surfactant thought to facilitate the

Received March 15, 1994; accepted July 1, 1994

Correspondence: Sam Hawgood, University of California, Box 0130, San Francisco, CA 94143.

Supported by Grant HL-24075 from the Heart, Lung, and Blood Institute of the National Institutes of Health and a Career Investigator Award from the American Lung Association. adsorption of surfactant phospholipids to the alveolar fluid surface (2). Using the prematurely delivered rabbit pup model of surfactant deficiency, Yamada et al. (8) reported that SP-A had a positive effect on lung mechanics when added back to an organic solvent extracted surfactant. Taken together these results suggest SP-A has a role in normal surfactant activity.

Many investigators have reported the inhibitory effects of plasma proteins on the biophysical activity of surfactants in vitro $(9-12)$. Plasma proteins leak into the alveolar air spaces during lung injury and may contribute to the decreased surfactant activity of lavage fluid reported for patients with acute lung injury (13). Plasma leakage may also be a factor contributing to the decreased response to exogenous surfactants seen in the presence of pulmonary edema (14). The susceptibility of different surfactants to inhibition by proteins varies depending on the composition and concentration of the surfactant $(15,16)$. SP-A appears to be particularly effective in protecting surfactants containing SP-B and SP-C from inhibition by plasma proteins in vitro $(17,18)$. Using a premature rabbit model of surfactant deficiency we examined the effect of increasing 
amounts of human plasma on a complete natural dog surfactant (containing SP-A, SP-B, and SP-C), on a dog lung surfactant extract (containing only SP-B and SP-C), and on a surfactant extract supplemented with SP-A.

\section{METHODS}

Preparation of surfactants and SP-A. To obtain complete DLS, the lungs were removed from exsanguinated dogs, degassed, and lavaged three times at $4^{\circ} \mathrm{C}$ with $1000 \mathrm{~mL}$ of buffer per lavage. The buffer used for the lavage and all subsequent experiments was $5 \mathrm{mM}$ Tris- $\mathrm{HCl}, 100 \mathrm{mM} \mathrm{NaCl}, \mathrm{pH}$ 7.4. The pooled lavage was spun at $150 \times$ for $15 \mathrm{~min}$ to remove cellular materials. The supernatant was spun at $20000 \times g$ for $15 \mathrm{~h}$ using a type 19 rotor in an LS50B ultracentrifuge (Beckman, Palo Alto, CA), and the resulting pellet dispersed in buffer containing 1.64 M sodium bromide. After equilibration for $1 \mathrm{~h}$, this suspension was spun at $100000 \times g$ for $4 \mathrm{~h}$ in a swinging bucket rotor. The pellicle was resuspended in buffer and washed. This pellet was resuspended in normal saline at $10 \mathrm{mg}$ phospholipid/mL and used as DLS. Phospholipid concentrations were calculated from the phosphorus content (19).

DLSE was isolated from DLS. Briefly, DLS was injected through a 22 -gauge needle into a 50 -fold excess by volume of 1-butanol and stirred at room temperature for $1 \mathrm{~h}$. After centrifugation at $1000 \times g$ for $20 \mathrm{~min}$, the supernatant was dried under vacuum and the residue was suspended in $0.9 \%$ $\mathrm{NaCl}$ by rotary mixing at $42^{\circ} \mathrm{C}$ for $15 \mathrm{~min}$. This surfactant has the same lipid composition as DLS but contains only SP-B and SP-C. SP-A was isolated from DLS. To recover SP-A, the proteins precipitated during butanol extraction were dried under nitrogen and washed twice in buffer containing $20 \mathrm{mM}$ octyl- $\beta$-D-glucopyranoside. The proteins insoluble in this

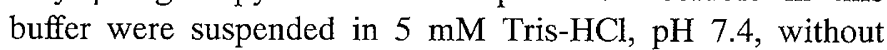
$\mathrm{NaCl}$ and dialyzed against the same buffer for $48 \mathrm{~h}$ with six changes of buffer. The insoluble materials were removed by centrifugation at $100000 \times g$ for $30 \mathrm{~min}$, and the supernatant containing SP-A was assayed for protein concentration (20) and stored in small aliquots at $-20^{\circ} \mathrm{C}$. We have previously reported in detail the lipid and protein composition of these surfactant fractions and the purity and activity of the SP-A isolated using these methods $(3,21)$.

Preparation of samples for ventilation and surface activity studies. Aliquots of DLS or DLSE containing a total of $3 \mathrm{mg}$ of phospholipid were incubated in $145 \mathrm{mM} \mathrm{NaCl}, 5 \mathrm{mM} \mathrm{CaCl}_{2}$ at $37^{\circ} \mathrm{C}$ for $10 \mathrm{~min}$ then centrifuged in a microfuge for $10 \mathrm{~min}$. After incubation in calcium, all the phospholipid was recovered in the pellet. The pellets were resuspended in $0.3 \mathrm{~mL}$ of normal saline or dilutions of human plasma in normal saline. The final phospholipid concentration in all samples was 10 $\mathrm{mg} / \mathrm{mL}$. Before the addition of SP-A, $0.3 \mathrm{~mL}$ of DLSE in normal saline (phospholipid concentration, $10 \mathrm{mg} / \mathrm{mL}$ ) was incubated at $37^{\circ} \mathrm{C}$ for $10 \mathrm{~min}$. SP-A (20\% by weight) was added to the sample. After an additional 10-min incubation at $37^{\circ} \mathrm{C}, \mathrm{CaCl}_{2}$ was added to a concentration of $5 \mathrm{mM}$ and the sample centrifuged. The pellet containing DLSE with bound $\mathrm{SP}-\mathrm{A}$ was resuspended in $0.3 \mathrm{~mL}$ of undiluted human plasma (protein concentration of $62.5 \mathrm{mg} / \mathrm{mL}$ ). The human plasma used for the studies reported here was collected from a single donor by the blood bank at the University of California San Francisco. Additional studies to be reported elsewhere were performed with other plasma samples with similar results.

Surface activity. The speed of surface tension lowering by the surfactants was measured in an adsorption chamber. Samples of the three surfactants (DLS, DLSE, and DLSE plus SP-A) in various dilutions of human plasma were mixed at a phospholipid concentration of $10 \mathrm{mg} / \mathrm{mL}$ and incubated at $37^{\circ} \mathrm{C}$ for $1 \mathrm{~h}$ in either $145 \mathrm{mM} \mathrm{NaCL}$ or $145 \mathrm{mM} \mathrm{NaCl}, 2.5$ $\mathrm{mM} \mathrm{CaCl}_{2}$. Three $\mathrm{mL}$ of buffer $\left(145 \mathrm{mM} \mathrm{NaCl}, 2.5 \mathrm{mM} \mathrm{CaCl}_{2}\right.$, $10 \mathrm{mM}$ Tris-HCl, $\mathrm{pH}$ 7.4) was added to a circular Teflon trough $2 \mathrm{~cm}$ in diameter in a humidified chamber at $37^{\circ} \mathrm{C}$. The sample containing $100 \mu \mathrm{g}$ of phospholipid was carefully layered on the bottom of the trough, stirring started at $240 \mathrm{rpm}$, and surface tension continuously measured by a roughened platinum dipping plate suspended from a strain gauge (Statham Gold Cell, Hato Ray, Puerto Rico). The signal was amplified and displayed on a strip chart recorder.

Preterm ventilated rabbit model. Pregnant New Zealand White rabbits at $27 \mathrm{~d}$ of gestation were given $1 \mathrm{~mL}$ of tetracaine $\mathrm{HCl} 1 \%$ intrathecally for anesthesia. Two min before opening the uterus, each fetus received $0.5 \mathrm{mg}$ of sodium pentobarbital and $4 \mu \mathrm{g}$ of pancuronium bromide intraperitoneally through the uterine wall. Four pups with similar weights (about $30 \mathrm{~g}$ ) were chosen from the litter for each experiment. The tracheas were cannulated with 18-gauge angiocaths and $0.3 \mathrm{~mL}$ of the surfactant containing $3 \mathrm{mg}$ of phospholipid or 0.3 $\mathrm{mL}$ of the saline vehicle was instilled into the trachea. Care was taken to squeeze gently on the chest until lung fluid appeared at the catheter hub to create a fluid-to-fluid interface and optimize surfactant distribution. The instillates were pushed into the lungs by the injection of $0.4 \mathrm{~mL}$ of air. Care was taken to avoid reflux and loss of material. The pups were placed in individual temperature-controlled plethysmograph chambers (22). Each pup was ventilated with a separate ventilator (Sechrist Infant Ventilator model IV-100 B, Sechrist Industries, Inc., Anaheim, CA) for 30 min with $100 \%$ oxygen at a rate of 48 breaths $/ \mathrm{min}$ with an inspiratory time of $0.35 \mathrm{~s}$, a PEEP of $4 \mathrm{~cm} \mathrm{H}_{2} \mathrm{O}$ and a PIP of $40 \mathrm{~cm} \mathrm{H}_{2} \mathrm{O}$. The ECG, airway flow, tidal volume, and proximal airway pressure were recorded on each pup every 3-5 min. The PIP on each ventilator was adjusted to keep the tidal volume at 6 to $7 \mathrm{~mL} / \mathrm{kg}$. All other ventilator settings remained constant. Ctot $\left(\mathrm{mL} / \mathrm{cm} \mathrm{H}_{2} \mathrm{O} /\right.$ $\mathrm{kg}$ ) was calculated by dividing the tidal volume by the difference between PIP and PEEP. With the ventilatory pattern and frequency used, airway flows were nearly zero at end PIP and PEEP.

Pressure-volume measurements. After $30 \mathrm{~min}$ of ventilation, the endotracheal tube was plugged for $10 \mathrm{~min}$ to allow the lungs to degas. The animals were transferred to a water bath at $37^{\circ} \mathrm{C}$ and connected to an apparatus for measurement of pressure-volume characteristics as previously described (22). The airway pressure was increased from 0 to $30 \mathrm{~cm} \mathrm{H}_{2} \mathrm{O}$ in $5-\mathrm{cm}$ $\mathrm{H}_{2} \mathrm{O}$ increments each minute. The airway pressure was then decreased at the same rate. The volume of air entering and leaving the lung was recorded just before each pressure change. 
Data analysis. All values are expressed as means and SEM. Comparisons between treatment groups were made by one-way analysis of variance, with a $p$ value of 0.05 considered significant. Unless otherwise stated, all treatment group comparisons are between littermates.

\section{RESULTS}

Surface activity. Plasma had a dose-dependent inhibitory effect on the surface activity of all the surfactant samples tested, but there was a marked difference between samples with respect to the plasma concentration required to inhibit activity. The surface tensions reached after $3 \mathrm{~min}$ of adsorption by DLS, DSLE, and DLSE plus SP-A suspended in various dilutions of plasma in either $145 \mathrm{mM} \mathrm{NaCl}$ or $145 \mathrm{mM} \mathrm{NaCl}, 5 \mathrm{mM} \mathrm{CaCl}_{2}$ are shown in Figure 1. A threshold plasma protein to phospholipid ratio (mg protein to $\mathrm{mg}$ phospholipid) for inhibition of adsorption was established by extending the steep part of the inhibition curves shown in Figure 1 to the $x$ axis. The thresholds for inhibition were DLSE 0.0007 , DLSE in $5 \mathrm{mM} \mathrm{CaCl}_{2}$ 0.007 , DLS 0.07, and DLSE plus SP-A in $5 \mathrm{mM} \mathrm{CaCl}_{2} 0.7$. With the surfactant concentration tested, the addition of SP-A to DLSE increased the threshold for plasma inhibition 70-fold, and the DLSE supplemented with SP-A had a resistance to inhibition comparable to complete DLS.

Ctot and PIP. The effects of plasma mixed with the three surfactants on lung mechanics (PIP and Ctot) during the $30 \mathrm{~min}$ of ventilation are shown in Figures 2-5. Pups given DLS in saline had a significantly higher Ctot and required a significantly lower PIP than littermates given saline only. Plasma in concentrations of $6.25,20.3$, and $62.5 \mathrm{mg} / \mathrm{mL}$ had no effect on the activity of DLS during ventilation (Figs. 2 and 3). Pups given DLSE in saline also had higher Ctot and needed lower PIP compared with littermate controls given saline only. In

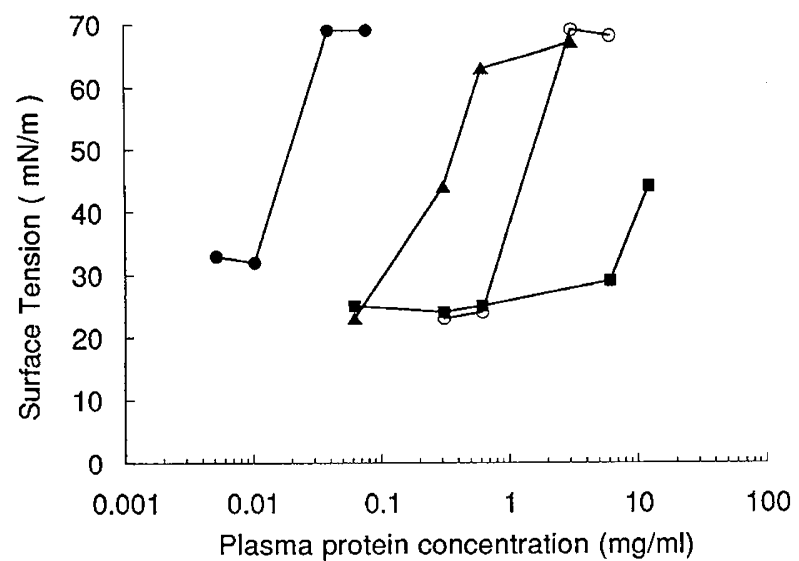

Figure 1. Surface adsorption in vitro. Surface adsorption was measured at $37^{\circ} \mathrm{C}$ by recording the change in surface tension of a clean surface of Tris 10 $\mathrm{mM}, \mathrm{NaCl} 145 \mathrm{mM}, \mathrm{CaCl}_{2} 2.5 \mathrm{mM}, \mathrm{pH} 7.4$, after placing the surfactant sample below the surface and starting stirring. The surface tension reached by each surfactant $3 \mathrm{~min}$ after stirring was started is shown as a function of plasma concentration in the sample. The samples $(10 \mathrm{mg} / \mathrm{mL}$ phospholipid) were incubated with the various plasma concentrations for $10 \mathrm{~min}$ before placing them in the adsorption chamber. The final concentration of surfactant phospholipid in the chamber was $33 \mu \mathrm{g} / \mathrm{mL}$. Filled circles, DLSE in saline; triangles, DLSE in saline $+2.5 \mathrm{mM} \mathrm{CaCl}$; empty circles, DLS in saline; squares, DLSE supplemented with SP-A in saline $+\mathrm{CaCl}_{2}$.

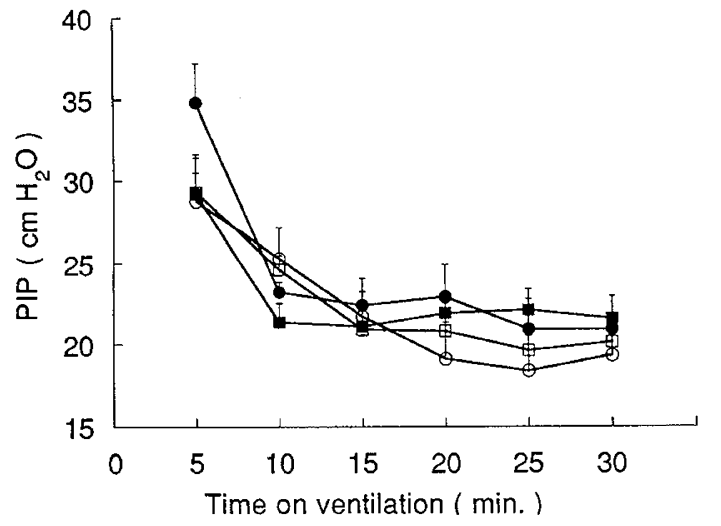

Figure 2. Effect of DLS on PIP during ventilation in the presence of increasing plasma concentrations. During ventilation the PIP was adjusted to maintain a tidal volume of $6-7 \mathrm{~mL} / \mathrm{kg}$. The values shown are mean and SEM for values obtained during each 5-min period for four to 11 animals in each group. Empty circles, DLS in 0 plasma; filled circles, DLS in $6.25 \mathrm{mg} / \mathrm{mL}$ plasma; empty squares, DLS in $20.3 \mathrm{mg} / \mathrm{mL}$ plasma; and filled squares, $62.5 \mathrm{mg} / \mathrm{mL}$ plasma. No significant effect of plasma on DLS activity was seen.

contrast to the results with DLS, the pups given DLSE showed decreased Ctot and needed higher PIP in plasma concentrations above $20.3 \mathrm{mg} / \mathrm{mL}$ (Figs. 3 and 4). Despite this deterioration in performance with increasing plasma, DLSE in all concentrations of plasma remained significantly better than saline alone.

In a littermate comparison of the effects of undiluted plasma $(62.5 \mathrm{mg} / \mathrm{mL})$ on DLSE and DLSE supplemented with SP-A, the PIP was significantly lower in the presence of SP-A (Fig. 5). In the presence of $62.5 \mathrm{mg} / \mathrm{mL}$ plasma, the Ctot in the presence of SP-A was significantly greater than that in the absence of SP-A at $20 \mathrm{~min}$ of ventilation $(0.334 \pm 0.118$ to $0.249 \pm 0.046)$ but the difference at $30 \mathrm{~min}$ did not reach significance $(0.332 \pm 0.122$ to $0.251 \pm 0.058)$. The PIP and Ctot obtained with DLSE plus SP-A in plasma were not significantly different from those obtained in nonlittermates treated with complete DLS.

Pressure-volume behavior. Pups given DLSE in saline or plasma had significantly greater lung volumes at all points of the pressure-volume maneuver than pups given saline only

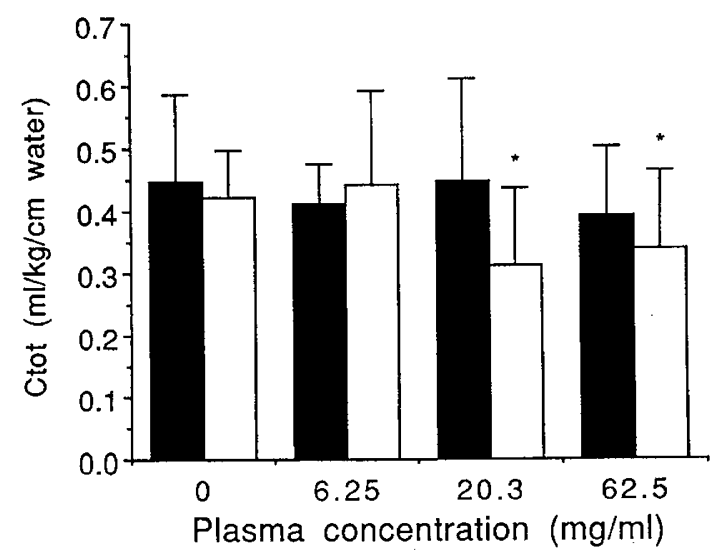

Figure 3. Total lung-chest compliance after $30 \mathrm{~min}$ of ventilation. The values shown are the mean and SEM for four to 12 animals in each group. Solid bars, DLS; empty bars, DLSE. No significant effect of plasma on DLS was seen. With DLSE the Ctot was significantly lower $\left(^{*}\right)$ in $20.3 \mathrm{mg} / \mathrm{mL}$ plasma and $62.5 \mathrm{mg} / \mathrm{mL}$ plasma than in 0 plasma. 


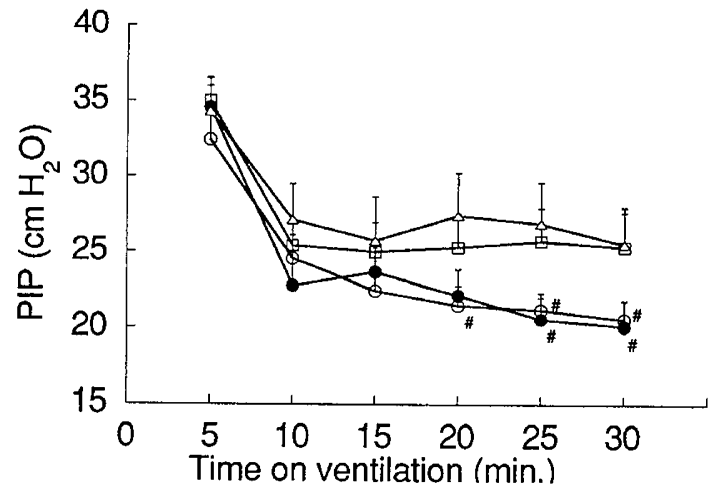

Figure 4. Effect of DLSE on PIP during ventilation in the presence of increasing plasma concentrations. During ventilation the PIP was adjusted to maintain a tidal volume of $6-7 \mathrm{~mL} / \mathrm{kg}$. The values shown are mean and SEM for values obtained during each 5-min period for eight to 10 animals in each group. Empty circles, DLSE in 0 plasma; filled circles, DLSE in $6.25 \mathrm{mg} / \mathrm{mL}$ plasma; empty squares, DLSE in $20.3 \mathrm{mg} / \mathrm{mL}$ plasma; and empty triangles, DLSE in $62.5 \mathrm{mg} / \mathrm{mL}$ plasma. The PIP from $20-30 \mathrm{~min}$ for 0 plasma or 6.25 $\mathrm{mg} / \mathrm{mL}$ plasma was significantly lower (\#) than for $20.3 \mathrm{mg} / \mathrm{mL}$ or $62.5 \mathrm{mg} / \mathrm{mL}$ plasma.

(Fig. 6). A dose-dependent effect of plasma on the air volume retained during deflation was seen in the pups given DLSE (Fig. 6). The deflation volumes from 30 to $5 \mathrm{~cm} \mathrm{H}_{2} \mathrm{O}$ airway pressure were significantly lower in animals treated with DLSE suspended in plasma at protein concentrations of 20.8 and 62.5 $\mathrm{mg} / \mathrm{mL}$ compared with DLSE suspended in normal saline or plasma at a protein concentration of $6.25 \mathrm{mg} / \mathrm{mL}$. The addition of SP-A to DLSE significantly improved the deflation stability of the lungs in the presence of undiluted plasma (Fig. 7).

\section{DISCUSSION}

Surfactant deficiency at birth makes it difficult for the newborn to inflate its lungs. As the infant makes increasingly vigorous attempts to ventilate noncompliant lungs, delayed

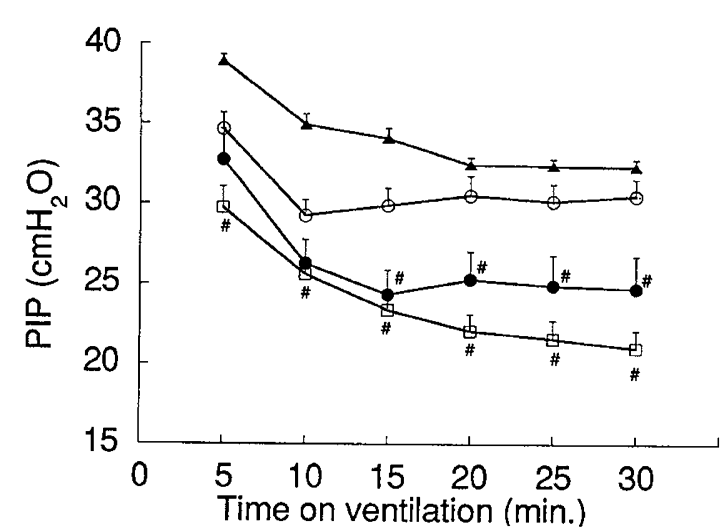

Figure 5. Effect of SP-A on PIP during ventilation in the presence of undiluted plasma. During ventilation the PIP was adjusted to maintain a tidal volume of $6-7 \mathrm{~mL} / \mathrm{kg}$. The values shown are mean and SEM for values obtained during each 5-min period for seven to 12 animals in each group. Squares, DLSE in 0 plasma; filled circles, DLSE supplemented with SP-A in $62.5 \mathrm{mg} / \mathrm{mL}$ plasma; empty circles, DLSE in $62.5 \mathrm{mg} / \mathrm{mL}$ plasma; and triangles, saline vehicle only. The PIP from 15-30 min for DLSE supplemented with SP-A in plasma was significantly lower (\#) than the PIP for DLSE in plasma. No significant difference was seen between DLSE without plasma and DLSE with SP-A in plasma.

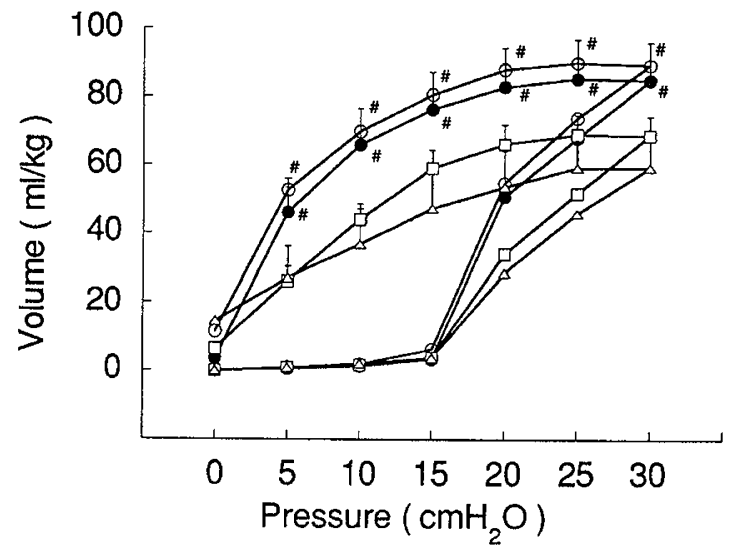

Figure 6. Effect of DLSE on pressure-volume characteristics of the lung with increasing plasma concentrations. The values shown are the mean and SEM from four to seven animals in each group. Empty circles, DLSE in 0 plasma; filled circles, DLSE in $6.25 \mathrm{mg} / \mathrm{mL}$ plasma; squares, DLSE in $20.3 \mathrm{mg} / \mathrm{mL}$ plasma; and triangles, DLSE in $62.5 \mathrm{mg} / \mathrm{mL}$ plasma. The volumes on deflation for 0 plasma and $6.25 \mathrm{mg} / \mathrm{mL}$ plasma were significantly (\#) higher than those for $20.3 \mathrm{mg} / \mathrm{mL}$ plasma or $62.5 \mathrm{mg} / \mathrm{mL}$ plasma.

adsorption of lung fluid, pulmonary edema, epithelial damage, and extravasation of plasma proteins into air spaces occur causing progressive respiratory distress. The interaction between extravasated plasma proteins and surfactant may also play a role in the pathogenesis of other forms of lung disease including pneumonia and adult RDS. Previously, many in vitro studies have shown that various substances including plasma proteins and lung edema fluid can inhibit surfactant function $(9-12)$. In the only published report of experimental surfactant inhibition in vivo, Kobayashi et al. (23) reported that airway edema protein inhibited the activity of surfactant-CK in a model of RDS similar to that used in our study (23). Surfactant-CK, prepared by organic solvent extraction of porcine alveolar wash surfactant, contains SP-B and SP-C. The extrac-

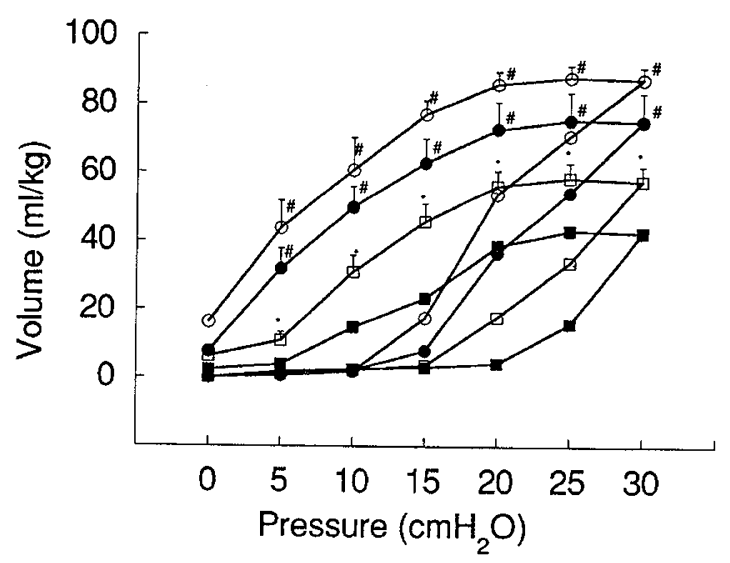

Figure 7. Effect of SP-A on pressure-volume characteristics of the lung in the presence of undiluted plasma. The values shown are the mean and SEM from four to eight animals in each group. Empty circles, DLSE in 0 plasma; filled circles, DLSE supplemented with SP-A in $62.5 \mathrm{mg} / \mathrm{mL}$ plasma; empty squares, DLSE in $62.5 \mathrm{mg} / \mathrm{mL}$ plasma; filled squares, saline vehicle only. The volumes on deflation were significantly higher (\#) for DLSE in 0 plasma and DLSE supplemented with SP-A in $62.5 \mathrm{mg} / \mathrm{mL}$ plasma than the deflation volumes in DLSE in $62.5 \mathrm{mg} / \mathrm{mL}$ plasma or saline alone. The volumes on deflation were significantly higher $\left(^{*}\right)$ for DLSE in $62.5 \mathrm{mg} / \mathrm{mL}$ plasma than the deflation volumes in saline alone. 
tion removes SP-A from the surfactant. Our study demonstrates for the first time that SP-A effectively protects surfactant extracts from inhibition by plasma in a premature rabbit model.

Although the mechanisms underlying surfactant inhibition are not well understood, it appears that a number of different proteins prevent or decrease surfactant phospholipid adsorption when the concentration of protein is sufficiently high relative to the surfactant concentration (9). At high protein concentrations, an interfacial film of denatured protein would form very rapidly and could prevent the adsorption of surfactant lipids. The results of our adsorption studies show plasma has a concentration-dependent effect of the activity of both complete natural surfactants and surfactant extracts. Other investigators have reported the important effects of surfactant concentration and subphase conditions on the concentration of inhibitor required for threshold inhibition in vitro $(11,24)$. These results and the unknown relationship between the concentrations of surfactant and inhibitors in the lung have led to uncertainties concerning the physiologic importance of surfactant inhibition in vivo. An example of the differences between in vitro and in vivo effects is seen in our results, where potent in vitro inhibition of DLS was seen at a plasma to surfactant ratio of 0.07 but no in vivo inhibition was seen at ratios as high as 6 . Because we were unable to directly measure either surfactant or protein concentrations in the lungs during ventilation, we cannot exclude rapid changes in the ratio of inhibitor to surfactant after instillation. The ventilator support, particularly the level of PEEP, used in this study may also have compensated for a loss of surfactant activity and decreased our ability to record the physiologic effects of significant changes in surfactant activity (25).

Despite these limitations of the model, we found that the in vitro studies related well to the in vivo studies in the rank order of surfactant resistance to inhibition. DLSE is a surfactant extract containing SP-B and SP-C but no SP-A. DLSE has good activity in vitro and in vivo in the absence of plasma and as shown gives comparable results to DLS in rabbit pups with RDS ventilated with $4 \mathrm{~cm} \mathrm{H}_{2} \mathrm{O}$ of PEEP. DLSE was the surfactant most sensitive to plasma inhibition of activity in both the surface balance and the rabbit pups. Supplementing DLSE with SP-A restored a level of resistance to inhibition by plasma comparable to complete DLS in vitro and in vivo. The mechanism by which SP-A protects surfactant activity in the presence of plasma is unknown, but it is possible that previously reported synergistic effects of SP-A on surfactant lipid adsorption rates may be important $(3,17,18)$. A more rapidly adsorbing surfactant would be expected to more effectively "compete" for the interface in the presence of other "surfaceseeking" substances including some plasma proteins. Many other mechanisms of both inhibition and protection including direct interactions between plasma and surfactant components could also be proposed.

It is hard to relate the absolute amount or concentration of plasma used in this study to levels potentially present in clinical lung disease. Seeger et al. (10) reported total protein to phospholipid ratios of 10 or more in the bronchoalveolar lavage fluid of patients with adult RDS. Using a nondilutional distal airway sampling technique, Matthay et al. (26) measured protein concentrations as high as $110 \mathrm{mg} / \mathrm{mL}$ in pulmonary edema fluid. Our experimental conditions therefore may approximate those found in some forms of lung injury. If this is so, our results suggest that SP-A plays an important role in maintaining surfactant activity under these conditions.

Acknowledgment. The authors thank Edward Hamilton for editorial assistance.

\section{REFERENCES}

1. Avery ME, Mead $J 1959$ Surface properties in relation to atelectasis and hyaline membrane disease. Am J Dis Child 97:517-523

2. Hawgood S, Clements JA 1990 Pulmonary surfactant and its apoproteins. J Clin Invest $86: 1-6$

3. Hawgood S, Benson BJ, Schilling J, Damm D, Clements JA, White RT 1987 Nucleotide and amino acid sequences of pulmonary surfactant protein SP 18 and evidence for cooperation between SP 18 and SP 28-36 in surfactant lipid adsorption. Proc Natl Acad Sci USA 84:66-70

4. White RT, Damm D, Miller J, Spratt K, Schilling J, Hawgood S, Benson B, Cordell B 1985 Isolation and characterization of the human pulmonary surfactant apoprotein gene. Nature 317:361-363

5. Curstedt T, Jörnvall H, Robertson B, Bergman T, Berggren P 1987 Two hydrophobic low-molecular-mass protein fractions of pulmonary surfactant. Characterization and biophysical activity. Eur J Biochem 168:255-262

6. Tanaka Y, Takei T, Aiba T, Masuda K, Kiuchi A, Fujiwara T 1986 Development of synthetic lung surfactants. J Lipid Res 27:475-485

7. Suzuki Y, Fujita Y, Kogishi K 1989 Reconstitution of tubular myelin from synthetic lipids and proteins associated with pig pulmonary surfactant. Am Rev Respir Dis 140:75-81

8. Yamada T, Ikegami M, Tabor BL, Jobe AH 1990 Effects of surfactant protein-A on surfactant function in preterm ventilated rabbits. Am Rev Respir Dis 142:754-757

9. Holm BA, Enhorning G, Notter RH 1988 A biophysical mechanism by which plasma proteins inhibit lung surfactant activity. Chem Phys Lipids 49:49 -55

10. Seeger W, Stöhr G, Wolf HRD, Neuhof H 1985 Alteration of surfactant function due to protein leakage: special interaction with fibrin monomer. J Appl Physiol 58:326338

11. Fuchimukai T, Fujiwara T, Takahashi A, Enhorning G 1987 Artificial pulmonary surfactant inhibited by proteins. J Appl Physiol 62:429-437

12. Ikegami M, Jobe A, Berry D 1986 A protein that inhibits surfactant in respiratory distress syndrome. Biol Neonate 50:121-129

13. Hallman M, Spragg R, Harrell JH, Moser KM, Gluck L 1982 Evidence of lung surfactant abnormality in respiratory failure. Study of bronchoalveolar lavage phospholipids, surface activity, phospholipase activity, and plasma myoinositol. J Clin Invest 70:673-683

14. Jobe A, Ikegami M 1987 Surfactant for the treatment of respiratory distress syndrome. Am Rev Respir Dis 136:1256-1275

15. Seeger W, Gunther A, Thede C 1992 Differential sensitivity to fibrinogen inhibition of SP-C- vs. SP-B-based surfactants. Am J Physiol 261:L286-L2191

16. Holm BA, Venkitaraman AR, Enhorning G, Notter RH 1990 Biophysical inhibition of synthetic lung surfactants. Chem Phys Lipids 52:243-250

17. Cockshutt AM, Weitz J, Possmayer F 1990 Pulmonary surfactant-associated protein A enhances the surface activity of lipid extract surfactant and reverses inhibition by blood proteins in vitro. Biochemistry 29:8425-8429

18. Venkitaraman AR, Hall SB, Whitsett JA, Notter RH 1990 Enhancement of biophysical activity of lung surfactant extracts and phospholipid-apoprotein mixtures by surfactant protein A. Chem Phys Lipids 56:185-194

19. Bartlett GR 1959 Phosphorus assay in column chromatography. J Biol Chem 234:466-468

20. Lowry OH, Rosebrough NJ, Farr AL, Randall RJ 1951 Protein measurement with the Folin phenol reagent. J Biol Chem 193:265-275

21. Hawgood S, Benson BJ, Hamilton Jr RL 1985 Effects of a surfactant-associated protein and calcium ions on the structure and surface activity of lung surfactant lipids. Biochemistry 24:184-190

22. Tooley WH, Clements JA, Muramatsu K, Brown CL, Schlueter MA 1987 Lung function in prematurely delivered rabbits treated with a synthetic surfactant. Am Rev Respir Dis 136:651-656

23. Kobayashi T, Nitta K, Takahashi R, Kurashima K, Robertson B, Suzuki Y 1991 Activity of pulmonary surfactant after blocking the associated proteins SP-A and SP-B. J Appl Physiol 71:530-536

24. Kobayashi T, Robertson B 1983 Surface adsorption of pulmonary surfactant in relation to bulk-phase concentration and presence of $\mathrm{CaCl}_{2}$. Respiration 44:63-70

25. Kobayashi T, Kataoka H, Ueda T, Murakami S, Takada Y, Kokubo M 1984 Effects of surfactant supplement and end-expiratory pressure in lung-lavaged rabbits. J Appl Physiol 57:995-1001

26. Matthay MA, Wiener-Kronish JP 1990 Intact epithelial barrier function is critical for the resolution of alveolar edema in humans. Am Rev Respir Dis 142:1250-1257 